\title{
Contribuições gramscianas sobre raça, identidade cultural e velhice na perspectiva de Stuart Hall
}

\section{Elaine Lima da Silva}

Universidade Federal de Santa Catarina (UFSC)
Juceli Aparecida da Silva

Universidade Federal de Santa Catarina (UFSC)

Contribuições gramscianas sobre raça, identidade cultural e velhice na perspectiva de Stuart Hall Resumo: Este artigo contextualiza um recorte a respeito das contribuições gramscianas apresentadas a partir da perspectiva de Stuart Hall. Utiliza-se das temáticas do racismo e da identidade cultural, cotejando-os ao fenômeno do envelhecimento. Apresenta um diálogo entre teorias, conceitos e suas relevâncias para a contemporaneidade. O estudo conclui que o envelhecimento não é um processo homogêneo e que suas características gerais são definidas especificamente pelos momentos históricos em que ocorrem.

Palavras-chave: Raça. Identidade cultural. Velhice. Gramsci. Stuart Hall.

Gramscian Contributions about Race, Cultural Identity and Aging in the Perspective of Stuart Hall Abstract: This article contextualizes a profile of Gramscian contributions presented from the perspective of Stuart Hall. It uses the themes of racism and cultural identity, comparing them to the phenomenon of aging. It presents a dialog between theories, concepts and their contemporary importance. The study concludes that aging is not a homogeneous process and that its general characteristics are specifically defined by the historic moments in which it occurs.

Keywords: Race. Cultural Identity. Aging. Gramsci. Stuart Hall. 


\section{Introdução}

$\mathrm{O}$ artigo se propõe a gerar reflexões que rompam com pensamentos enrijecidos e homogêneos, conforme é sugerido nas obras de Gramsci $(1987 ; 2000 ; 200 a ; 2004 ; 2008 ; 2010)$, a partir das análises realizadas por Stuart Hall $(2003 ; 3003 a)$ sobre raça e identidade cultural, como também, de apontamentos a respeito do processo de envelhecimento humano ${ }^{1}$.

Faz-se válido introduzir que o pensador italiano Antonio Gramsci nasceu em Sardenha (1891-1937). Foi um intelectual político e ativista socialista ao longo de toda sua vida e esteve engajado com os problemas de sua época. Passou vinte anos sob condenação em diversas instituições prisionais sem jamais desistir de sua luta. Durante esse longo período, acessou somente o que lhe era propiciado por amigos e familiares. Assim, não pôde se inserir em outros contextos que não tivessem como centralidade sua própria sociedade. Neste período, Gramsci escreveu trinta e três cadernos que ficaram conhecidos como Cadernos do Cárcere (SCHLESENER, 1992; DEL FRA, 1977), cujo desenvolvimento esteve ligado à explanação sobre as questões políticas de seu país, a construção socialista na Europa ocidental e oriental e ao fracasso das revoluções socialistas nas sociedades capitalistas desenvolvidas do Ocidente. Gramsci discorreu a respeito do surgimento do fascismo e sobre a função que o partido possuía na construção da hegemonia no Continente (HALL, 2003). Expôs seus pensamentos a respeito dos mais distintos pontos históricos, filosóficos, literários econômicos e científicos (MEZZAROBA, 2005).

De acordo com Schlesener (1992, p. 9), Gramsci refletiu e reformulou os principais conceitos marxistas sem deixar de sê-lo, mas os refinando através de uma "contínua tentativa de superar um modo de viver e de pensar atrasado, como o que era próprio de um sardo do princípio do século, para apropriar-se de um modo de viver e de pensar não mais regional e de aldeia, mas nacional e, tanto mais nacional quanto inserido nos modos de viver e de pensar europeus”. Para Hall (2003, p. 300), Gramsci foi "um dos primeiros 'teóricos marxistas' das condições históricas que dominaram a segunda metade do século vinte". Conceitos tais como Estado e classe social, por exemplo, foram reformulados pelo autor italiano que criticava as formas de pensar de sua época. Observava a necessidade de compreender que havia imensas discrepâncias histórico-sociais (SCHLESENER, 1992). Hall (2003) salienta que Gramsci nunca fora um marxista essencialmente doutrinário, ortodoxo ou religioso, pois compreendia que a teoria de Marx precisava ser aplicada em outras condições históricas e desenvolvimentos sociais dos quais, tanto Marx quanto Engels não previram e, assim, expandindo-a.

Hall (2003; CARLEY, 2013) provavelmente foi um dos poucos intelectuais a correlacionar os trabalhos de Gramsci com um discurso racial e de identidade cultural, tornando possível, também, apresentar-se esta tão peculiar contribuição à contemporaneidade, contemplando compreensões sobre velhice. Os escritos de Gramsci não tratam sobre raça e etnia, identidade cultural, colonialismo e imperialismo, enquanto questões contemporâneas, mas suas experiências, cognições e formação permitem que seus escritos sejam analisados a partir dessa perspectiva. Mesmo que suas obras estejam fragmentadas, possuam limitações devido ao tempo cronológico em que foram escritas e sejam concretas demais ao local ao qual se destinavam, elas oferecem contribuições e reflexões a serem pensadas para além desses contextos. Diante das limitações ao qual o Gramsci foi submetido, seus Cadernos podem ser considerados resultados impressionantes de sua proeza intelectual e riqueza teórica (HALL, 2003; SCHLESENER, 1992). Para Carley (2013), as características dos escritos gramscianos, são novas formas de ideias, paradigmas e, assim, mostram-se como novas possibilidades para se pensar contemporaneamente os fenômenos sociais racionalmente estruturados.

\section{Raça e identidade cultural}

Para Carley (2013), um dos principais pontos desenvolvidos por Gramsci em seus Cadernos do Cárcere e que podem ser corroborados aos estudos sobre raça (racismo) e identidade cultural na contemporaneidade, estão contidos em suas correspondências, em especial, ao tratar sobre pontos pertinentes ao sul (GRAMSCI, 1987) e, também, ao analisar criticamente os escritos de Marx. No primeiro caso, observa-se que "Gramsci apresenta sua concepção de raça não através de quadros sociológicos ou antropológicos, mas, sim, através de quadros filosóficos, teológicos, e humanísticos especificamente através do catolicismo" (CARLEY, 2013, p. 56). O catolicismo se apresentou como uma ferramenta fundamental para o desenvolvimento das questões sobre raça e racismo em Gramsci (1987). Isto transforma seu rico trabalho relevante aos contextos históricos e políticos, pois demonstrou a forte herança histórica que a Igreja forneceu ao desenvolvimento da Itália desde a Idade Média, especialmente aos camponeses do sul (CARLEY, 2013; REIS, 2007). Além disso, Gramsci - nascido em uma família pobre do sul - tinha vasto entendimento a respeito da divisão de classe que existia entre o norte e o sul da Itália. O norte do país se apresentava como uma região modernizada, industrial e independente. Já o sul era uma região rural, subdesenvolvida, 
dependente e estigmatizada pela formação de identidades culturais e por preceitos fascistas. Para Gramsci (1987, p. 64) "é preciso que, como sempre ocorre, não seja os vasos de argila os que se quebrem entre os vasos de cobre que a nave tomada pela borrasca sacode e agita". Nestas elucubrações "se percebe algumas colocações de Gramsci sobre o fascismo, sobre a diferença social entre Norte e Sul, sobre as representações partidário-sindicais dos operários, sobre a presença e importância da Igreja Católica no seu país, sobre a relação entre os intelectuais e as classes subalternas etc.” (REIS, 2007, p. 2).

No que tange as questões de inter-relacionamentos quanto classe e raça, Gramsci se mostrou irredutível. Hall (2003) observa que esse é um problema teórico difícil e complexo de ser abordado e que, com frequência, leva a posicionamentos extremados por parte de quem o lê. Gramsci contextualizou possibilidades não reducionistas ao propor a existência de não apenas um único princípio determinante de articulação: a raça, a identidade cultural ou a classe, pois ora seus pensamentos privilegiam as relações das classes subjacentes, onde todas as forças de trabalho étnica ou racialmente diferenciadas estão submetidas à mesma relação de exploração no capital; ora circunstancia seus discursos na centralidade das identidades e divisões étnicas e raciais em detrimento da estruturação de classe fundamental à sociedade. $\mathrm{O}$ racismo é apresentado a partir de uma de suas características consideradas mais comuns e, também, menos explicadas pelas teorias que tratavam do assunto. Esta é justamente a submissão das vítimas do racismo aos embustes das próprias ideologias racistas que as aprisionam e definem (MEZZAROBA, 2005; GRAMSCI, 1987; 2000; 2000a; 2004; 2008; 2010; CARLEY 2013; HALL, 2003). Fica evidenciado que os elementos distintos e contraditórios dos diferentes acontecimentos históricos podem estar entrelaçados e integrados aos mais variados discursos ideológicos; "mas também a natureza e o valor da luta ideológica que busca transformar as ideias populares e o "senso comum' das massas" (HALL, 2003, p. 333). As contribuições gramscianas apontadas por Hall quanto à análise das ideologias racistas no centro da luta ideológica, são pertinentes inclusive para as reflexões contemporâneas (CARLEY, 2013). Já no que diz respeito a sua análise crítica dos escritos de Marx (1996), Gramsci (2004, p. 126) gerou uma intensa polêmica, pois, para ele, a revolução Russa era:

a revolução contra $O$ Capital de Karl Marx. O Capital de Marx era, na Rússia, o livro dos burgueses, mais do que dos proletários. Era a demonstração crítica da fatal necessidade de que na Rússia se formasse uma burguesia, se iniciasse uma era capitalista, se instaurasse uma civilização de tipo ocidental, antes que o proletariado pudesse sequer pensar em sua desforra, em suas reivindicações de classe, em sua revolução. Os fatos superaram as ideologias. Os fatos fizeram explodir os esquemas críticos dentro dos quais a história da Rússia deveria se desenvolver segundo os cânones do materialismo histórico.

Neste artigo, escrito em sua juventude, Gramsci reflete a questão do fascismo e a intensificação das repressões políticas sofridas não somente na Itália, mas, também, na Europa, no fortalecimento dos Estados Unidos e no nascimento da União Soviética. A desaprovação de Gramsci "sobre a ausência do sujeito popular nas grandes decisões nacionais é um dos exemplos claros da leitura dialética e democrática que o teórico sardo faz da realidade. Gramsci critica uma ausência produzida na relação não orgânica entre os intelectuais tradicionais e o povo e imposta por uma classe dominante temerosa de perder o controle político-econômico da sociedade" (PROTÁSIO, 2008, p. 74). Somente através da política seria possível a transformação social de relações discriminatórias, opressoras e que assim, constroem identidades culturais fragilizadas e sufocadas pela alienação do trabalho baseado no consumo capitalista. Para Gramsci, indiscutivelmente a liberdade tinha um papel central nessa discussão (PROTÁSIO, 2008). A identidade cultural, dentro dessas constatações, exprime-se como identidade construída e modelada em benefício do domínio e da exploração capitalista. Através do racismo, discrimina e estigmatiza determinados grupos e identidades, denegrindo-os, como observados nas questões que afligiam aos italianos do sul do país.

Os escritos de Gramsci promovem o questionamento sobre a validade da lei geral do valor e a sua tendência em fazer com que as pessoas homogeinizem a força de trabalho em toda a época capitalista. Gramsci se afasta dos tradicionais modelos eurocêntricos de desenvolvimento capitalista utilizados em sua época e, assim, apresenta a possibilidade de observação das distintas maneiras pela qual o capital consegue preservar e adaptar seus objetivos centrais de controle e exploração frente à força de trabalho, tornando-a parte de seus regimes (HALL, 2003). Reconhece que, mesmo a exploração frente ao capital sendo a mesma, o sujeito de classe não é homogêneo ${ }^{2}$. Sempre “diferencia o processo condicional, os 'momentos' e o caráter contingente da passagem de uma 'classe em si' a uma 'classe por si' ou dos momentos do desenvolvimento 'econômicocorporativo' ao 'hegemônico"” (HALL, 2003, p. 330). Seus questionamentos problematizam e impossibilitam noções simplistas dos acontecimentos históricos, pois nem mesmo o próprio momento hegemônico é compreendido como algo simples em sua percepção. Em Gramsci, o momento hegemônico está fundado nas alianças estratégicas que vão sendo feitas e não pode ser visto enquanto uma identidade previamente definida. 
Ao longo de sua vida política Gramsci foi contrário ao economicismo e reducionismo provenientes do marxismo clássico. Considerou a análise das classes e de outras forças sociais como forças políticas, forçando a saída do estudo da própria política do velho modelo esquemático utilizado. A política fazia parte de formações estruturalmente complexas e para tanto, seu estudo deveria abarcar conceitos e termos próprios. Assim, partindo da perspectiva analítica, histórica e conceitual da vida de Gramsci, é que Hall (2003), constata ser possível interromper os raciocínios homogeneizadores que até então circundavam os estudos sobre racismo e identidade cultural. Somos facilmente seduzidos a acreditar que o racismo deseja uma prática anti-humana e antissocial, como sendo algo igual e estático. Mas, a partir das análises gramscianas, compreende-se que mais significantes do que as características gerais do racismo, são as maneiras pelas quais essas características vão sendo remodeladas e resignificadas pela especificidade histórica dos contextos e ambientes nos quais elas vão ocorrendo. Estes fatores também se mostram determinantes quanto à construção das identidades culturais. Dessa forma, o que se leva em consideração não é o racismo (fascismo), mas a existência de diversas formas discriminatórias e estigmatizantes de racismos.

Da mesma maneira em que não existe um único racismo, também, não existe uma única lei de desenvolvimento homogênea (HALL, 2003). É a partir da análise dos textos escritos por Gramsci que se torna possível compreender a importância das tensões e das contradições que são geradas pelas irregularidades dos compassos e direções tomadas pelo desenvolvimento histórico. Assim, a influência do racismo e das estruturas ao qual pertence, nas identidades culturais, é penetrante, porém, não ocorrendo em todos os pontos da formação social, ou seja: não é regular nem homogeneizadora (CARLEY, 2013; HALL, 2003). Gramsci não articulava os fenômenos sociais como coisas e sim como sistemas de relações nos quais as identidades culturais iam se formando (PROTÁSIO, 2008).

\title{
Velhice
}

Simone de Beauvoir (1991) escreveu sobre como os chineses, os judeus e os gregos agiam a respeito de seus velhos. Em suas constatações, observou que, por exemplo, Confúcio, na China:

\begin{abstract}
justificava moralmente a autoridade, associando a velhice à posse da sabedoria; a longevidade para os judeus era considerada como ‘suprema recompensa da virtude'. Para os gregos, há um conflito no domínio dos mitos e das gerações [...]. As palavras gregas Géra, géron, significam ao mesmo tempo idade avançada e o privilégio da ancianidade, de honra ligada à velhice, virtude imprescindível para o conselho de anciãos ligado ao rei na antiga Pólis (SILVA, 2011, p. 22).
\end{abstract}

Magalhães (1989) complementa que a homogeneidade nunca pôde ser considerada uma característica da velhice, pois, ao longo das histórias humanas, os velhos sempre foram venerados ou denegridos. Os exemplos fornecidos pelos autores se mostram em sintonia com as contribuições gramscianas apresentadas por Hall (2003), pois demonstram a heterogeneidade do envelhecimento e a ambiguidade no modo de tratamento das pessoas idosas e que são definidas pelas formações históricas raciais e de identidades culturais aos quais são submetidas.

As vertentes de estudos pós-coloniais, culturalistas, subalternos, epistemologias do sul, entre outras, emergem como uma crítica ao pensamento e discurso eurocêntrico propondo novas formas de pensamento (HALL, 2003). Este discurso parece ter sido uma preocupação de Gramsci muito antes da criação destes termos, embora já utilizasse o conceito de classes subalternas, termo agregado sob a insígnia do proletariado urbano, rural, do subproletariado e da pequena burguesia. Todos desagregados na história da sociedade civil sob disputas pela hegemonia ${ }^{3}$. Em suas considerações sobre a questão racial a partir de Gramsci, Hall (2003, p. 326) considera que o racismo possui "características gerais entendidas enquanto estereótipos engessados sobre o que é raça e que são modificadas e transformadas pela especificidade histórica dos contextos e ambientes". Do mesmo modo, podemos compreender o fenômeno do envelhecimento humano também como possuidor de características gerais - do ciclo biológico, por exemplo -, mas que são estereotipados e engessados nos termos velho e velhice, porém mutáveis de acordo com as sociedades e suas especificidades históricas. $\mathrm{O}$ envelhecimento possui características gerais, mas ainda mais significantes são as formas pelas quais essas características gerais, entendidas enquanto estereótipos engessados sobre a velhice e os velhos, que são modificadas e transformadas pela especificidade histórica dos contextos e ambientes. É preciso muito pouco para que sejamos persuadidos a aceitar a opinião enganosa de que o envelhecimento é igual em todas as situações, seja em suas formas, suas relações com as outras estruturas e processos ou em seus efeitos (HALL, 2003). Estas constatações se dão, pois, ora as categorias como velhice e envelhecimento estão atreladas aos modos de produção das sociedades, influenciando como homens e mulheres envelhecem e de como a distinção que 
Gramsci faz entre a classe em si e a classe por si podem servir enquanto ferramenta teórica para (re)pensar o processo de aposentadoria, por exemplo. Ora, porque a questão do aumento da expectativa de vida não é um fato estático, nem localizado, ele alterna em diferentes períodos históricos, atendendo às inúmeras causas e relações de força, não podendo atribuir, no sentido de Gramsci, a um tipo de economismo ou reducionismo que reduziria às análises da raça/etnia, identidade cultural e envelhecimento apenas a determinantes econômicos. Para Hall (2003, p. 303-304) o economismo é entendido como reducionismo teórico específico, pois ele tende "a ler as fundações econômicas da sociedade como a única estrutura determinante [...] simplifica a estrutura das formações sociais, reduzindo sua complexidade de articulação vertical e horizontal a uma única linha de determinação". Dessa forma, equipara todos os diferentes níveis existentes em uma sociedade.

A dinâmica social do envelhecimento envolve uma complexidade de fenômenos sociais, não só econômicas, sobredeterminantes entre si e conduzidas no fluxo das relações entre a sociedade civil e a sociedade política. Não há uma homogeneidade no envelhecimento. Ele está atrelado às relações de forças em cada formação social, em contextos específicos de cada momento histórico. Dado seu caráter biológico (nascer, viver, envelhecer e morrer), há certa tendência em normatizá-lo, via ideologias hegemônicas que determinam o envelhecimento, na contemporaneidade, com um tipo:

que deve ser almejado por todos os que estão vivendo a velhice, os que estão envelhecendo e os que irão envelhecer: cuidando de si com tecnologias rejuvenescedoras, amparada pela mídia e pela oferta crescente de kits anti rugas, cremes, remédios, comprimidos Viagra e cirurgias que prometem devolver a juventude. Esse tipo 'Idoso (a) Universal' estigmatiza os que não se enquadram neste perfil, culpando-os (as) por seu declínio natural da velhice (SILVA, 2011, p. 40-41).

O impacto do aumento da expectativa de vida não é um fato natural, mas condicionado por fatores econômicos, políticos, sociais, demográficos, culturais, das dialéticas das relações entre estrutura e superestrutura e, por conseguinte, produzem efeitos distintos que determinarão leis específicas e novas lutas hegemônicas. Gramsci faz a distinção entre a classe em si e a classe por si, enquanto diferentes estágios em que a consciência, a organização e a unidade de classe, sob determinadas condições, podem se desenvolver. Primeiramente, o estágio do corporativismo econômico em que grupos reconhecem seus interesses básicos comuns, mas não tem consciência das solidariedades de classe mais ampla. Num segundo momento, o estágio do corporativismo de classe em que a solidariedade de interesses de classe se desenvolve, mas somente no campo econômico. E o estágio da hegemonia, que transcende o limite corporativo da solidariedade econômica pura, engloba os interesses de outros grupos subordinados e começa a se propagar pela sociedade, promovendo a unidade intelectual, moral, econômica e política e propondo também as questões em torno das quais as lutas acontecem (HALL, 2003).

Partindo-se das perspectivas de Hall (2003, p. 327) a respeito do racismo, considera-se que o preconceito ao envelhecimento, as práticas e estruturas sociais na contemporaneidade ocorrem em alguns setores da formação social, mas nem todos: "Não há 'lei de desenvolvimento' homogênea que afete da mesma forma cada faceta de uma formação social. Precisamos compreender melhor as tensões e contradições geradas pelos compassos e direções irregulares do desenvolvimento histórico". O impacto do aumento da expectativa de vida não é um fato natural, mas condicionado por fatores econômicos, políticos, sociais, demográficos, culturais, das dialéticas das relações entre estrutura e superestrutura e, por conseguinte, produzem efeitos distintos que determinarão leis específicas, novas lutas hegemônicas, entre outros fenômenos. Propõe-se a partir disso, pensar a aposentadoria, ainda no seu processo de transição do trabalho e das lutas dos trabalhadores por melhores salários e outras reivindicações, encabeçadas ou não por sindicatos. Numa primeira instância, nesse exemplo proposto, os trabalhadores de uma dada fábrica, estando em processo de aposentadoria podem se reconhecer num tipo de corporativismo econômico, ou seja, constatando alguns de seus direitos básicos, talvez não tanto com a mesma garra dos trabalhadores mais novos. Nesse corporativismo ainda não possuem uma consciência mais ampla, imersos que estão ainda no cotidiano do trabalho, não refletem sobre ele. Num segundo momento, os mesmos trabalhadores podem se reconhecer num tipo de corporativismo de classe, enquanto um grupo de aposentados de fato, unidos por interesses econômicos, duvidosos das vantagens da aposentadoria que se aproxima cada vez mais. Logo irão perder muito dos seus rendimentos e talvez já lhes preocupe como irão lidar com o tempo de aposentado. Assim, unem-se por estes temores, mas ainda mais pelo temor da perda financeira. E, finalmente, se percebem para além do limite corporativo da solidariedade econômica pura, englobando outros interesses para além de trabalhadores ou de aposentados, mas também os seus direitos enquanto cidadãos, homens e idosos.

A própria formação de classe envolve outros elementos que não somente a esfera econômica. Fatores como gênero, raça, identidade cultural, trajetórias de vida, contextos locais, subjetividades diversas, entre ou- 
tros, são sobredeterminantes num processo de aposentadoria. Este último estágio descrito aqui, não deve ser tomado como definitivo ou decisivo, pois: "Gramsci nos alerta que mesmo esse grau extraordinário de unidade orgânica não garante o resultado das lutas específicas, que podem ser perdidas ou ganhas" (HALL, 2003, p. 311). Tomar a análise, por exemplo, sobre um grupo de pessoas aposentadas, de modo reducionista, somente levando em consideração aspectos da classe ou fatores econômicos, inviabiliza uma compreensão mais geral do fenômeno do envelhecimento. Especialmente no Brasil, consideramos não ser possível compreender o fenômeno do envelhecimento sem levar em conta aspectos como classe, raça, identidade cultural e gênero. A abordagem não redutiva das questões que concernem aos interrelacionamentos de classe, raça, identidade cultural, gênero e envelhecimento, significa compreender que tais termos são imagens em reflexo um do outro. Para Hall (2003, p. 328), "o fato de Gramsci adotar uma abordagem não redutiva para as questões de classe, junto com sua compreensão da conformação profundamente histórica de qualquer formação social específica, ajuda a apontar o caminho para uma abordagem não reducionista das questões da raça e classe", e, acrescentamos, às questões do envelhecimento.

Diferenças identitárias, étnicas, de raça, gênero e etárias podem ser explicadas enquanto um conjunto de antagonismos dos mais variados (econômicos, políticos e ideológicos) na classe ao qual há submissão de formas mais ou menos semelhantes de exploração. Isto ocorre quando se utiliza abordagens redutivas que privilegiam apenas a classe, por exemplo, onde o pressuposto é de que se a exploração frente ao capital é o mesmo, então, erroneamente se acredita que o sujeito de classe também o é (HALL, 2003). Motta (2009) nos adverte quanto à existência de diferenças biológicas próprias de cada sexo, com trajetórias sociais diferenciadas e desiguais. Levantar bandeiras anunciando somente estas diferenças dentro do processo de envelhecimento pode obscurecer outras formas de debate pertinentes

O impacto do aumento da expectativa de vida não é um

fato natural, mas condicionado por fatores econômicos, políticos, sociais, demográficos, culturais, das dialéticas das relações entre estrutura e superestrutura e, por conseguinte, produzem efeitos distintos que determinarão leis específicas, novas lutas hegemônicas, entre outros fenômenos. ao assunto, como as questões de classe, raça/etnia, identidade, geração, e todas as outras particularidades e subjetividades que permeiam o envelhecimento humano tanto para os homens quanto para as mulheres (SILVA, 2011).

\section{Considerações finais}

A perspectiva apresentada por Hall evidencia as singularidades do pensamento de Gramsci que perpassaram por toda sua obra ao longo de sua carreira como intelectual, ativista, jornalista, socialista e comunista. Através de seus estudos sobre os acontecimentos históricos e políticos na Itália e Europa, pode-se constatar que as contribuições gramscianas permitiram a Hall tecer correlações entre os conceitos de Gramsci e seus próprios conceitos a respeito de cultura, raça e identidade cultural. As análises sobre os escritos de Gramsci possuem limitações devido às fragmentações existentes em seus escritos e, também, devido ao momento histórico em que o autor viveu. Mesmo se aproximando dos teóricos marxistas e de Hall, considerado um pósmoderno, foi possível ultrapassar as barreiras de suas vinculações teórico-intelectuais e fazer uso de seus conceitos na contemporaneidade, ressignificando as proposições de Gramsci. Por meio das análises de Hall foi possível perceber a relevância do pensamento e dos estudos de Gramsci para o cenário marxista não ortodoxo atual, promovendo a reflexão sobre várias formas de dominação, inclusive no que concerne aos conceitos engessados e estereotipados aos quais fomoslsomos submetidos. Dessa maneira, podem-se compreender os fenômenos culturais como expressões da sociedade, ou seja, como um conjunto de práticas sociais interligadas que moldam e são moldadas historicamente.

Conclui-se que o sujeito de classe é compreendido como sujeito não homogêneo, seja como sujeito em que se analisa sob a perspectiva da raça, da identidade cultural ou do envelhecimento. A identidade se dá pelas alianças estratégicas e não pela perspectiva de uma identidade dada, definida. Mais significantes do que as características gerais do racismo, da identidade ou do envelhecimento, são as formas pelas quais essas caracte- 
rísticas gerais são modificadas e transformadas pela especificidade histórica dos contextos e ambientes nos quais elas se tornam ativas. Deve-se levar em consideração não o racismo, mas os racismos, não a identidade, mas as identidades e, por fim, não somente a velhice, mas as velhices. O sujeito idoso está inserido nas diversas esferas da sociedade civil, está entrelaçado nas relações sociais a que pertence, fazendo parte de um organismo vivo inserido no mundo do trabalho, nas organizações políticas, sociais e culturais. É responsável pela elaboração de projetos na classe a que está vinculado englobando, não só a condição de idoso, mas de gênero, classe, identidade cultural e raça/etnia. Reconhece-se, por exemplo, que o fato de se ser mulher, negra, artesã, benzedeira e em condições de vida subalternas, pode alterar significativamente a experiência de envelhecimento em contraposição ao modelo universal geralmente vinculado pela mídia do homem branco, católico e 'heterossexual.

Reconhecer homens e mulheres enquanto seres históricos que se constroem durante toda a sua existência é reconhecer suas potencialidades de engajamento social responsável através de suas identificações ao longo da vida, incluindo seu envelhecimento. Assim, conclui-se que urge a necessidade de intelectuais engajados na luta pelo reconhecimento da capacidade de homens e mulheres, independentemente de idade, classe, identidade, raça/etnia, gênero, legitimar seus direitos.

\section{Referências}

BEAUVOIR, S. A velhice. Rio de Janeiro: Nova Fronteira, 1991.

CARLEY, R. Agile Materialisms: Antonio Gramsci, Stuart Hall, Racionalization, and Modernity. Journal of Historical Sociology. v. 6, ed. 4. p. 413-441. Disponível em: http://apps.webofknowledge.com/full_record.do?product=UA\&search_mode= GeneralSearch\&qid=1\&SID=3AsqgZFWAdBnhBQkynM\&page=1\&doc=2. Acesso em: 14 dez. 2014.

DEL FRA, L. Antonio Gramsci: os dias do cárcere. 1977. Disponível em: https://www.youtube.com/watch?v=7m0XFL-OHaA. Acesso em: 01 dez. 2014.

GRAMSCI. A. Americanismo e fordismo. Tradução de Gabriel Bogossian. São Paulo: Hidra, 2008.

. Caderno 12 [1932]: Apontamentos e notas dispersas para o grupo de ensaios sobre a história dos intelectuais. In: Cadernos

do Cárcere. Rio de Janeiro: Civilização Brasileira, v. 2, 2000. p. 13-53.

p. $82-86$.

Carta a Tatiana Schutz (7 de setembro de 1931). In: Cartas do Cárcere. Rio de Janeiro: Civilização Brasileira, v. 2, 2000a.

Escritos Políticos. Vol. 1, Rio de Janeiro: Civilização Brasileira, 2004.

O sul e a guerra. In: A questão meridional. (Org.) Felice Franco de Parlato. Rio de Janeiro: Paz e Terra, 1987.

2010. p. 51-55.

Socialismo e Cultura. In: Escritos políticos. Tradução de Paollo Nosella. Recife: Fundação Joaquim Nabuco: Massangana,

HALL, S. A relevância de Gramsci para o estudo de raça e etnicidade. In: HALL, S. Da diáspora: identidades e mediações culturais. Belo Horizonte: UFMG, 2003. p. 294-334.

. Stuart Hall por Stuart Hall. In: HALL, S. Da diáspora: identidades e mediações culturais. Belo Horizonte: UFMG, 2003a. p. 404-433.

LACLAU, E. Depoimento [nov. 2013]. “La última entrevista de Ernesto Laclau con La Nacion”. Entrevista concedida a SEHINKMAN, Diego, La Nación, 13 abr. 2014.

MAGAlHÃES, N. D. A Invenção Social da Velhice. Rio de Janeiro: Papagaio, 1989.

MEZZAROBA, O. Gramsci e a hegemonia. In:

(Org.). Gramsci: Estado e relações internacionais. Florianópolis: Fundação

Boiteux, 2005. p. 07-26.

MOTTA B. A. O homem idoso e sua participação social: lazer, militância política e cultural. In: Seminário envelhecimento masculino. 2009. SESC São Paulo.

PROTÁSIO, A. R. O marxismo gramsciano: política e liberdade. Revista Espaço Acadêmico. Maringá: UEM, n. 83, abr. 2008. Disponível em: http://www.espacoacademico.com.br/083/83protasio.htm. Acesso em: 17 jan. 2015.

REIS, C. Herança histórica como elemento da questão nacional em Antonio Gramsci. Revista Urutágua. Maringá: DCS\UEM, n. 07, 2007. Disponível em: http://www.urutagua.uem.br/007/07reis.pdf. Acesso em: 17 jan. 2015.

SCHLESENER, H. A. Hegemonia e Cultura: Gramsci. Curitiba: UFPR, 1992.

SILVA, E. L. Velhices masculinas: um estudo sobre experiências do envelhecer. 2011. No prelo. Trabalho de Conclusão de Curso (Graduação em Ciências Sociais). Universidade Federal de Santa Catarina. Florianópolis, 2011.

\section{Notas}

1 Stuart Hall (1932-2014) nasceu na Jamaica. Vivenciou em sua própria família as tensões coloniais clássicas. Foi a partir da leitura das obras de Marx e do seu engajamento político que se identificou com os estudos de Gramsci (LACLAU, 2014). 
2 Apesar de escrito no singular, sujeito de classe é compreendido como plural e heterogêneo: eleleleslelalelas.

3 Odomínio da Europa burguesa iniciada no século 15 com as navegações assume, concomitante, outra versão hegemônica de dominaçãoe coerção: a do discurso científico moderno, que assume categorias binominais de exclusão (HALL, 2003).

\section{Elaine Lima da Silva}

Professora voluntária de Antropologia no Curso de Formação de Monitores da Ação Gerontológica do Núcleo de Estudos da Terceira Idade (NETI) da Pró-Reitoria de Extensão da Universidade Federal de Santa Catarina (UFSC).

Mestranda no Programa de Pós-Graduação em Sociologia Política (UFSC).

\section{Juceli Aparecida da Silva}

juceliiii@gmail.com

Mestranda no Programa de Pós-Graduação em Sociologia Política da Universidade Federal de Santa Catarina (UFSC).

\section{UFSC}

Campus Reitor João David Ferreira Lima, s/n - Trindade.

Florianópolis - Santa Catarina - Brasil

CEP: 88040-900 